\title{
ADVERSE EFFECTS OF PREMATURITY \\ IN EARLY CHILDHOOD OF CHILDREN FROM PLEVEN, BULGARIA
}

\author{
Kamburova M. ${ }^{1}$, S. Georgieva ${ }^{1}$ \\ 1. Departement of Public Health Sciences, Medical University - Pleven, Bulgaria \\ 1, Kliment Ochridscy,Str. \\ Pleven, 5800 \\ Bulgaria \\ e-mail: mariela_kamburova@yahoo.com
}

ABSTRACT

Prematurity has a negative impact on physical development and health by increasing the demand of health and social services in early childhood of preterm children.

\begin{abstract}
AIM
This paper aims to study the relationship between prematurity as a risk factor and physical growth retardation, poor health status and high demand of health and social services in early childhood of premature children in the town of Pleven, Bulgaria.
\end{abstract}

\section{MATERIAL AND METHODS}

A cohort follow-up study of children from birth up to 3 years of age was carried out.

The study was comprehensive for all premature children $(N=58)$ and representative for full-term infants $(N=192$, or $10.4 \%$ of all of the 1827 full-term children) born in 2007 at the University Hospital of Pleven and resided in the city of Pleven. Prospective data on determinants under study were collected from all children included in this study $(\mathrm{N}=250)$. The children were observed from January 2007 through July 2011.

Relative risk (RR) was calculated to determine the effect of prematurity as a risk factor.

\section{RESULTS}

It was found: statistically significant differences in the height and weight of preterm and term infants; higher risk for premature children to suffer more than five times a year from respiratory diseases compared to term infants $(R R=4.10$, $95 \% \mathrm{Cl} 1.89-8.85)$; more than five times more frequent involvement of the visual analyzer among preterm children compared with term infants $(\mathrm{RR}=5.42,95 \% \mathrm{Cl} 1.48-19.94)$; "consumers" with high consumption of health and social services are mainly pre-term born with low-birth weight children.

\section{CONCLUSION}

Our results indicate that prematurity increased the risk for preterm children living in urban areas for physical development retardation, poor health status and high demand of health and social services up to 3 years of age in region of Pleven. Findings from this study suggest the need for active health and educational actions by health professionals in the region in order to avoid premature births.

\section{Indexing terms/Keywords}

Keywords: children health, physical development of children, prematurity, risk factor

\section{Academic Discipline And Sub-Disciplines}

Medicine

\section{TYPE (METHOD/APPROACH)}

Research

\section{Council for Innovative Research}

Peer Review Research Publishing System

\section{Journal: Journal of Social Sciences Research}

Vol. 8 , No. 2

jssreditor.cir@gmail.com

www.jssronline.com 


\section{INTRODUCTION}

Prematurity is considered as one of the most important single cause of Global Burden of disease in the neonatal period, carrying a significant risk of early and delayed health problems $(1,2)$. It has a negative impact on physical development and health in early childhood by increasing the demand of health and social services in the preterm children $(3,4,5,6,7$, 8). The adverse health outcomes for preterm children increased with decreasing of gestational age at birth (9). Studies on complications in various organs and systems of premature children reported long-term impact of these diseases and negative effects over health, the growth and development of those children (10).

Premature children have poor physical development compared with term infants up to 3 years of age. Weight of children in early childhood depends on the gestational age at birth (11). In a study of Bocca-Tjeertes I et al. (2012) was established lower average height and weight in preterm children compared with term infants. Boyle E et al. (2012) found increasing the proportion of underweight children at age of 3 with decreasing of gestational age at birth. The proportion of underweight children (20\%) born before 32 weeks of gestation was 10 times higher than the proportion of underweight term infants (2\%).

According Pramana I et al. (2011) premature children suffered more often from respiratory diseases in the first year of life compared with term infants. Among preterm children $80 \%$ suffered from cough, $44 \%$ from breathlessness, $25 \%$ were hospitalized due to respiratory diseases and $13 \%$ needed continuous inhalation therapy due to dyspnea.

Individual quality care for premature infants in early childhood have a protective effect for developing chronic lung diseases - odds ratio (OR $=0.42,95 \% \mathrm{Cl} 0.18-0.95)(14)$.

It was found that $1-2 \%$ of all newborns have congenital or occurred during the perinatal period hearing problems. The risk of damage to hearing increased significantly for premature children. Among children who received mechanical ventilation the middle ear damaging is more often. It is proved significant hearing impairment requiring the use of hearing aid - 1 to $5 \%$ among children born before 25 weeks of gestation $(15,16)$.

The preterm children have significantly higher probability of getting ocular diseases and reduction of vision. The most common ocular abnormality in premature children is retinopathy of prematurity. Prevalence decreases with increasing of gestational age (17).

According Rautava L et al. (2013) prevalence among preterm children is directly related to the quality of health care at birth. Demand of health and social services in early childhood for premature children is higher compared with term infants. Hintz S et al. (2008) analyzed the consumption of services such as social care, home visit by a nurse, visits to specialists, rehabilitation of speech and others among extremely premature infants (born before 28 week of gestation). Between 18 and 22 months of their life more than $50 \%$ of children used more than three of those services, $19.1 \%$ used $6-7$ and $37 \%$ of premature infants are needed at least one health service.

However, prematurity as a public health issue has not been subject to scientific inquiry in Bulgaria in the past two decades. Yet, there are a small number of scientific publications in terms of risk factors for premature birth and effects of prematurity over health in early childhood in Bulgaria $(11,20)$.

This scientific study meets the need of analysis of some negative effects on prematurity in Bulgaria.

\section{AIM}

Study of the prematurity as a risk factor for physical growth retardation (height and weight), poor health status and high demand of health and social services in early childhood in the town of Pleven, Bulgaria.

We hypothesized a positive association between premature birth and physical development and health status of children. Furthermore, we assumed a positive link between premature birth and demand of health and social services in early childhood.

\section{MATERIAL AND METHODS}

\section{Study design}

A cohort follow-up study of physical growth, health status and demand of health care services among children from birth up to 3 years of age was carried out in town of Pleven, Bulgaria.

The 58 premature and 192 mature children were prospectively observed from January 2007 through July 2011. The study was comprehensive for premature children and representative for term infants born in 2007 in the town of Pleven. In order to avoid possible selection bias and to increase the accuracy and reliability of the results the group of term infants is higher and the ratio of the two groups of preterm and term infants was 1: 3.3.

Premature infants eligible for the study weighed $2500 \mathrm{~g}$ or less at birth, their gestational age was 37 weeks of gestation or less, and they resided in Pleven. Only 5 such infants were excluded on account of lack of consent from the parents.

Term infants were matched to premature infants by date of birth and they weighed more than $2500 \mathrm{~g}$, their gestational age was more than 37 weeks and they also resided in Pleven.

The newborns were divided into four groups due to gestational age and weight at birth:

Pre-term born with low-birth weight (PBLBW),

Pre-term born with normal birth weight (PBNBW,

Term-born with low-birth weight (TBLBW),

Term-born with normal birth weight (TBNBW).

One year after birth, the children were divided into two groups - premature and term born. They were followed up until they completed their third year (20). 


\section{Study area}

Pleven is a typical district town, located in Central North Bulgaria. At the beginning of the study (2007) the size of population of the city was 139573 people. The birth rate in 2007 was $8.96 \%$. The proportion of preterm infants among all live births was $7.7 \%$ which is close to the average level of indicator for the country - about $8 \%(21)$.

The city is provided with a full package of health services for outpatient and inpatient care.

\section{Study instruments:}

Document analysis: The information was derived from medical records of newborns in a neonatal clinic at the University Hospital, records of these children that were referred for care at an institution and records related to health care services used by children up to 3-years of age.

Interview: Information about the health and health care services was collected by face to face interview of parents during home visits.

Clinical Examination: An objective clinical examination of preterm and term infants was conducted in home visits. It included measurement of height, weight, health status and examination for optic and hearing problems.

Height is measured with centimeter and is classified as below normal, normal and above normal.

Weight is measured with scales and classified as underweight (below normal), normal and above normal.

The optic and hearing problems were diagnosed by using of glasses and / or hearing aid.

\section{Index for assessment of the demand of health and social services}

Assessment of the demand of health and social care services of preterm and term infants was made by adapted index which includes 5 main types of health and social services (22).

Treatment in intensive care unit after birth - yes or none;

Medical treatments given after birth - number of methods;

Average length of stay in a neonatal clinic after birth - days;

Referral for institutional care after birth - yes or none;

Re-admissions from birth up to 3 years of age - yes or none and number of re-admissions.

Consumption of each service was worth 1 point. The extent of the index is 5 (from 0 to 5 ). According the law of normal distribution studied children with 0,1 and 2 points had normal consumption of health and social services, and children with 3,4 and 5 points were "consumers" with a high level of consumption.

Special semi-structured questionnaire that contained 35 questions for demographic status, clinical manifestations and health and social services used by children from birth up to 3 years of age was designed for the purpose of the study.

Data were collected by the researchers.

Statistical analysis: Statistical analyses were performed using Statistical Package for Social Sciences (SPSS) 11.5. Comparison was performed using One-Way ANOVA (Bonferroni) test. Analysis of category parameters was performed with Chi-Square Test (and/or Fisher's exact test).

A value of $p<0.05$ was considered statistically significant.

Risk ratio (RR) was calculated to determine the risk of physical growth retardation (height and weight), poor health status and high demand of health and social services in early childhood for premature children.

Ethical Considerations: The right of privacy of the studied children was guaranteed. Only the leading investigator had access to the identification information. It was obtained informed consent from the mother / parents of the children studied that was certified in person with their name and signature in the questionnaire before the performance of the study.

\section{RESULTS AND DISCUSSION}

\section{Physical development of preterm and term infants up to 3 years of age}

The assessment of physical development of children was made on the basis of indicators of growth. The major of them are height and weight.

\section{- Height of children}

It was established statistically significant difference in the height of preterm and term infants: 1 year $(p=0.0002 ; r=0.34)$; 2 years $(p=0.0001 ; r=0.31)$ and 3 years $(p=0.005 ; r=0.32)$.

At the age of one $27.6 \%$ of the preterm children and $3.2 \%$ of term infants had height below normal. A significantly higher was proportion of term infants with normal height $(87.4 \%)$ compared with premature $(62.1 \%)$. The height above normal had $10.3 \%$ of preterm and $9.4 \%$ of term infants.

At two years of age was not registered full-term children with height below normal, and every fifth premature child were with height below normal. Among children with normal height dominated proportion of term infants (92.6\%) compared to preterm children (70\%). With height above normal were $10.4 \%$ of the preterm and $7.4 \%$ of term infants.

At three years of age every seventh prematurely child were shorter than normal (14.8\%). The normal height had $99.5 \%$ of term infants and $77.8 \%$ of the preterm children. Among children with height above the normal dominated proportion of premature children $(7.4 \%)$ compared to term infants $(4.5 \%)$. (Table 1$)$ 
Table 1 Distribution of the studied groups of children (in \%), according to their height and weight at 1-st, 2-nd and 3-rd year

Below Normal (\%)

Normal (\%)

Above Normal (\%)

\begin{tabular}{|c|c|c|c|c|c|c|c|c|c|c|c|c|}
\hline \multirow[t]{2}{*}{ Age } & \multicolumn{2}{|c|}{ Height } & \multicolumn{2}{|c|}{ Weight } & \multicolumn{2}{|c|}{ Height } & \multicolumn{2}{|c|}{ Weight } & \multicolumn{2}{|c|}{ Height } & \multicolumn{2}{|c|}{ Weight } \\
\hline & PM & $\mathbf{T}$ & PM & $\mathbf{T}$ & PM & $\mathbf{T}$ & PM & $\mathbf{T}$ & PM & $\mathbf{T}$ & PM & $\mathbf{T}$ \\
\hline $\begin{array}{l}\text { 1-st } \\
\text { year }\end{array}$ & 27.6 & 3.2 & 24.1 & 3.2 & 62.1 & 87.4 & 69.0 & 93.5 & 10.3 & 9.4 & 6.9 & 3.2 \\
\hline $\begin{array}{l}\text { 2-nd } \\
\text { year }\end{array}$ & 20.7 & 0.0 & 17.2 & 3.2 & 70.0 & 92.6 & 75.9 & 94.6 & 10.4 & 7.4 & 6.9 & 2.2 \\
\hline $\begin{array}{l}\text { 3-rd } \\
\text { year }\end{array}$ & 14.8 & 0.0 & 18.5 & 1.5 & 77.8 & 95.5 & 70.4 & 95.4 & 7.4 & 4.5 & 11.1 & 3.1 \\
\hline
\end{tabular}

PM - premature children; T - term born children

The study established statistically significant differences in the height of preterm and term infants: at first year of age (RR $=11.68,95 \% \mathrm{Cl} 4.31-31.64)$ and at third year $(\mathrm{RR}=22.96,95 \% \mathrm{Cl} 2.96$ to 88.56$)$.

\section{- Weight of children}

It was established a statistically significant difference in the weight of premature and term infants: 1 year $(p=0.0009 ; r=$ $0.32) ; 2$ years $(p=0.01 ; r=0.26)$ and 3 years $(p=0.002 ; r=0.34)$.

At age of one $24.1 \%$ of the preterm children and $3.2 \%$ of term infants were underweight. A proportion of term infants with normal weight $(93.5 \%)$ compared with preterm (69\%) was significantly higher. The weight above normal had $6.9 \%$ of the preterm and $3.2 \%$ of term infants.

At age of two $3.2 \%$ of term infants and $17.2 \%$ of the preterm children were underweight. The proportion of term infants with normal weight $(94.6 \%)$ was higher than proportion of preterm infants $(75.9 \%)$. With weight above normal were $6.9 \%$ of the preterm and $2.2 \%$ of term infants.

At the age of three the share of underweight premature children increased $(18.5 \%)$, while the share of term underweight children decreased to $1.5 \%$. The normal weight had $95.4 \%$ of term infants and $70.4 \%$ of the preterm children. The proportion of children with weight above normal among premature children was $11.1 \%$ respectively among term infants $3.1 \%$ (Table 1).

The study found a statistically significant difference in the weight of premature and term infants: at first year $(\mathrm{RR}=9.55$, $95 \% \mathrm{Cl} 3.47-26.25)$ and at third year $(\mathrm{RR}=14.77,95 \% \mathrm{Cl} 3.12-70.04)$.

Our findings of retardation in weight of premature babies were similar to the established by Boyle E et al. (2012) and the Bocca-Tjeertes I (2012).

\section{Health status of the children}

\section{- Suffering of children from respiratory diseases}

The respiratory diseases were the most common cause of illness among children in early childhood. According Pramana IA et al. (2011) premature children suffer more often from respiratory diseases in the first year of life compared with term infants.

The shares and term and preterm infants who had up to 3 times a year respiratory diseases was almost equal $-58.6 \%$ to $58.9 \% .13 .8 \%$ of the preterm and $32.6 \%$ of term infants got $4-5$ times a year such a diseases. The proportion of premature children who suffered more than 5 times a year from respiratory diseases (27.6\%) was more than three times higher compared to the proportion $(8.5 \%)$ of term infants $(p=0,03 ; r=0.26)$. (Fig. 1$)$ 


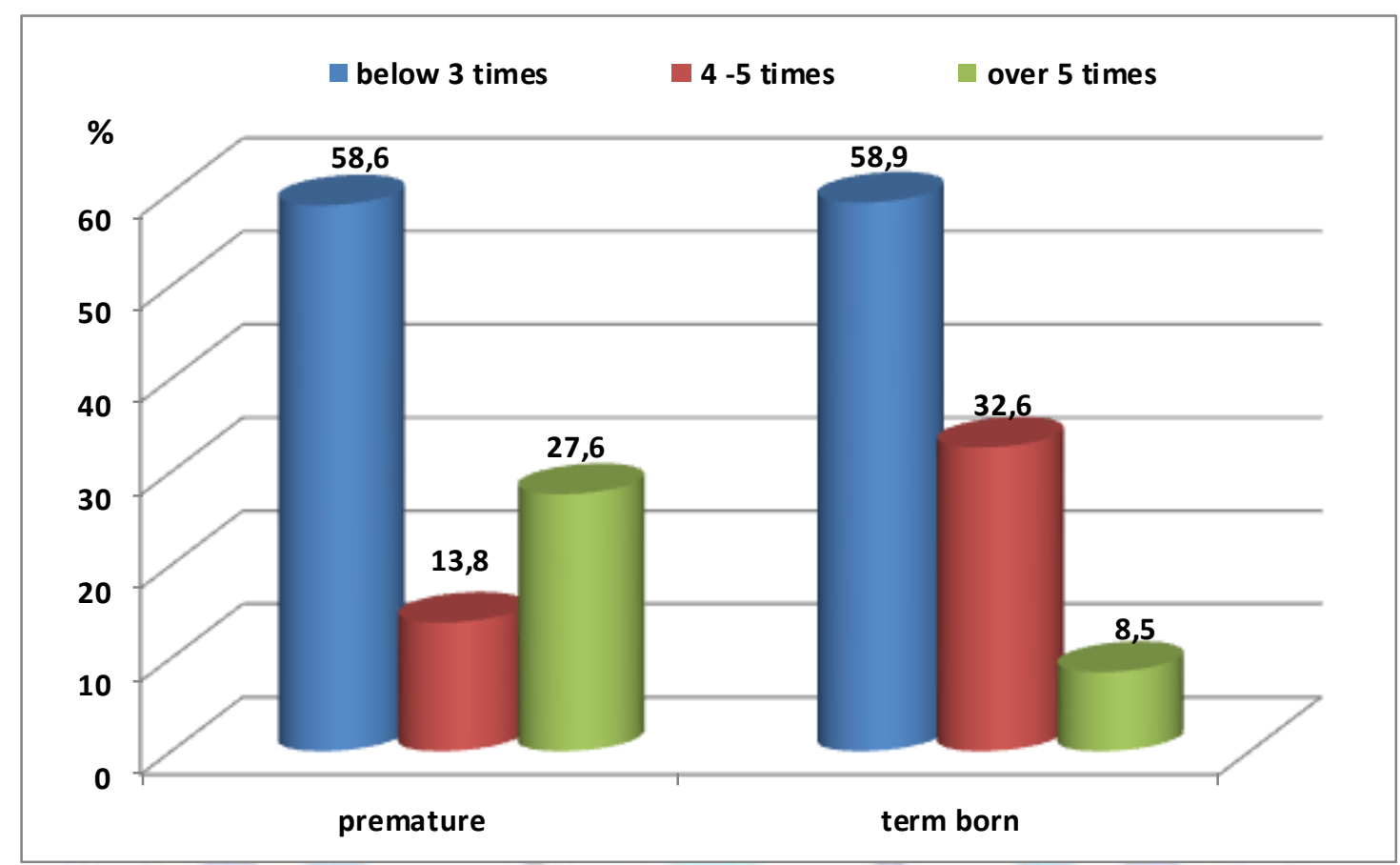

Fig. 1 Distribution of the studied groups of children (in \%), according to the suffering of respiratory diseases (times/per year)

Our results revealed respiratory diseases as the most common cause of illness among children studied and four times higher risk $(\mathrm{RR}=4.10,95 \% \mathrm{Cl} 1.89-8.85)$ premature children to suffer more than five times a year from respiratory diseases compared to term infants.

\section{- Vision}

Preterm children suffered five times more often from vision problems compared with term infants: vision problems had $10.3 \%$ of preterm children while the proportion of children with eye problems among term infants was $2.1 \%(p=0.047 ; r=$ $0.18)$.

We found more than five times more frequent involvement of the visual analyzer among preterm children compared with term infants $(R R=5.42,95 \% \mathrm{Cl} 1.48-19.94)$, which confirmed the results of Repka MX (2002) for significantly higher probability of involvement of all parts of the visual analyzer and reduction of vision in preterm children compared with term infants.

\section{- Hearing}

In literature $1-2 \%$ of all newborns have congenital or occurred during the perinatal period hearing problems.

Our results did not establish a statistically significant difference among the observed preterm and term infants in terms of hearing problems.

\section{Index of consumption of health and social services of preterm and term infants from birth to 3 years old}

It was found a statistically significant difference $(p=0.0001 ; r=0.62)$ between the four studied groups of children in terms of number of health and social services used in the period of early childhood.

Three of fourteen PBNBW children had not used health services and the rest were used 1 to 4 services. Among PBLBW children the highest was proportion of those who used four health and social services - 33.3\%, while only $2.9 \%$ of them were not consumed any service. $45.2 \%$ of TBNBW children used only one service and there is no child used 4 or 5 services. Only one TBLBW child not used any service and proportion of children consumed 4 services was $37.5 \%$.

According to the results of the study with normal consumption of health and social services, respectively 0,1 and 2 points were $52.4 \%$ of the children studied. The distribution of the children with normal use was as follows: $64.3 \%$ of PBNBW children; $18.6 \%$ of PBLBW children; $96.2 \%$ of TBNBW children and $52.5 \%$ by TBLBW children.

"Consumers" with high consumption of health and social services, respectively 3,4 and 5 points were 47.6 percent of the children studied, distributed in four groups as follows: $35.7 \%$ of PBNBW children; $81.4 \%$ of PBLBW of children; $3.8 \%$ of TBNBW children and $47.5 \%$ of TBLBW children.

As shown in Figure 2 with normal consumption was TBNBW and PBNBW children. "Consumers" with high consumption of health and social services were mainly PBLBW children. 


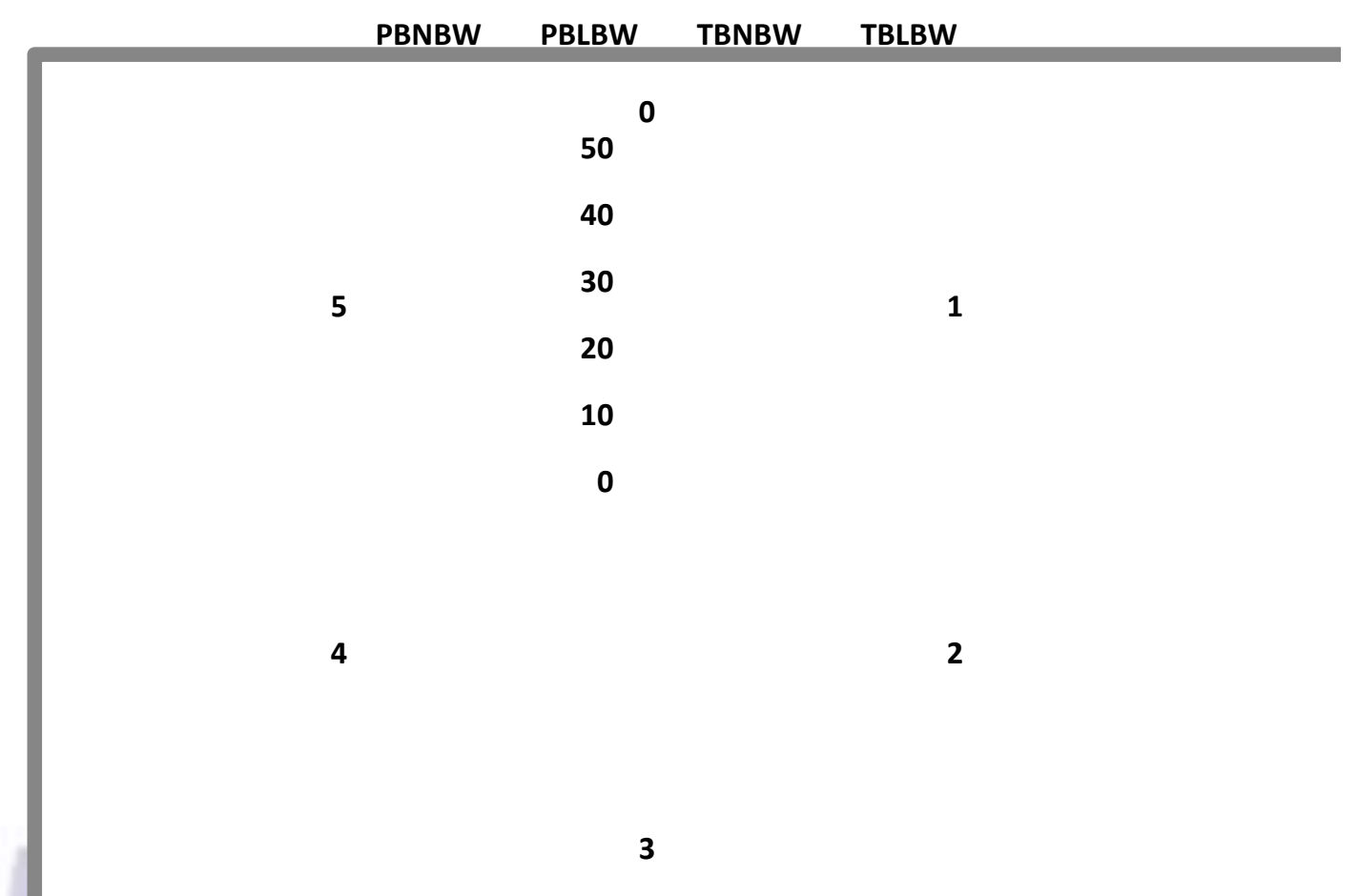

Fig. 2 Distribution of the studied groups of children, according the number of health and social services used (in \%)

According to the index for consumption of health and social services to studied children from birth up to 3 years of age with a high consumption of 3,4 and 5 points were identified $47.6 \%(119)$ of the children studied, respectively $81.4 \%$ of PBLBW and $3.8 \%$ of TBNBW and with normal consumption of 0,1 and 2 points $52.4 \%$ (131) of children, respectively $96.2 \%$ of TBNBW and $18.6 \%$ by PBLBW. (Table 2 )

Table 2 Distribution of the studied groups of children (in number and \%), according to the index for consumption of health and social services

\begin{tabular}{ccc}
\hline $\begin{array}{c}\text { Groups studied } \\
\mathbf{N}=\mathbf{2 5 0}\end{array}$ & $\begin{array}{c}\text { Normal consumption (\%) } \\
\mathbf{N = 1 3 1}\end{array}$ & $\begin{array}{c}\text { High consumption (\%) } \\
\mathbf{N = 1 1 9}\end{array}$ \\
\hline PBNBW & 64.3 & 35.7 \\
\hline PBLBW & 18.6 & $\mathbf{8 1 . 4}$ \\
\hline TBNBW & 96.2 & 3.8 \\
\hline TBLBW & 52.5 & 47.5 \\
\hline All & $\mathbf{5 2 . 4}$ & $\mathbf{4 7 . 6}$ \\
\hline
\end{tabular}

Our results were similar to those found of Hintz S et al. (2008), who analyzed consumption of health and social services of premature infants born before 28 weeks of gestation. Between 18 and 22 months of their life more than $50 \%$ of children consume more than three health services. The autors established that $37 \%$ of premature infants used at least one health service.

\section{CONCLUSION}

Our results indicate that prematurity increased the risk for preterm children living in urban areas for physical development retardation, poor health status and high demand of health and social services up to 3 years of age.

Findings from this study suggest the need for active health and educational actions by health professionals in the region in order to avoid premature births in Bulgaria.

\section{ACKNOWLEDGMENTS}

The authors are very grateful to the staff of the Obstetric Clinic at University Hospital in Pleven, Bulgaria, for their continuous support for the whole duration of this study.

\section{REFERENCES}

[1] The Global Burden of Preterm Birth. 2009. Lancet. 374(9697), 1214.

[2] Wang $\mathrm{H}$, Lidell $\mathrm{C}$, Coates $\mathrm{M}$ et al. 2013. Global, regional, and national levels of neonatal, infant, and under-5 mortality during 1990-2013: a systematic analysis for the Global Burden of Disease Study 2013. Lancet. 384.,957-979. 
[3] Escobar GJ, Clark RH, Greene JD. 2006. Short-term outcomes of infants born at 35 and 36 weeks' gestation: we need to ask more questions. Semin Perinatol. 30, 28-33.

[4] Greenough A. 2012. Long term respiratory outcomes of very premature birth (<32 weeks). Semin Fetal Neonatal Med. 2, 73-76.

[5] IOM. Preterm Birth: Causes, Consequences, and Prevention. 2007. Washington, DC. USA, National Academy Press.

[6] The European Health Report 2005. 2005. Public health action for healthier children and populations, World Health Organization.

[7] WHO. Born too soon: the global action report on preterm birth. 2012. Geneva, World Health Organization.

[8] WHO. The World Health Report 2005: Make every mother and child count. 2005. Geneva, World Health Organization.

[9] Boyle EM, Poulsen G et al. 2012. Effects of gestational age at birth on health outcomes at 3 and 5 years of age: population based cohort study. BMJ. 1, e896

[10] Kalantar-Zadeh K, Block G . et al. 2004. Reverse epidemiology of conventional cardiovascular risk factors in patients with chronic heart failure. Journal of the American College of Cardiology. 43, 1439-1444.

[11] Жечева, Я., И. Янкова, А. Начева. 2012. Честота на поднормено и наднормено телесно тегло при българските деца и подрастващи. Педиатрия. 1, 29-34. (article in Bulgarian with an abstract in English)

[12] Bocca-Tjeertes IF, van Buuren S et al. 2012. Growth of preterm and full-term children aged 0 to 4 years: integrating median grouth and variability in grouth charts. J Pediatr. 3, 460-456.

[13] Pramana IA, Latzin P et al. 2011. Respiratory symptoms in preterm infants: burden of disease in the first year of life. Eur J Med Res. 5, 223-230.

[14] Pittard WB. 2013. Well-child care in infancy and healthcare services utilization from birth to 6 years by late preterm children receiving Medicaid benefits. South Med J. 2, 173-179.

[15] Hintz SR, Kendrick DE et al. 2005. Changes in neurodevelopmental outcomes at 18 to 22 months' corrected age among infants of less than 25 weeks' gestational age born in 1993-1999. Pediatrics. 6, 1645-1651.

[16] Wood NS, Marlow N et al. 2000. Costeloe K, Gibson AT, Wilkinson AR. Neurologic and developmental disability after extremely preterm birth. New England Journal of Medicine. 6, 378-384.

[17] Repka MX. 2002. Ophthalmological problems of the premature infant. Mental Retardation and Developmental Disabilities Research Reviews. 4, 249-257.

[18] Rautava L, Eskelinen J et al. 2012. 5 - year morbidity among very preterm infants in relation to level of hospital care. JAMA Pediatr. 1, 40-46.

[19] Hintz SR, Kendrick DE et al. 2008. Community Supports After Surviving Extremely Low-Birth-Weight, Extremely Preterm Birth. Arch Pediatr Adolesc Med. 8, 748-755.

[20] Kamburova M, Georgieva S, Yankulovska SA. 2014. Health care consumption by premature children up to 3 years of age in Pleven, Bulgaria. AARJMD. 1, 88-97.

[21] WHO. Regional Office for Europe. Health for All Database, updated January 2014.

[22] Велкова А. 2001. Здравни и социални проблеми на старите хора, живеещи сами в селата. Докт. дис., Плевен. (PhD thesis in Bulgarian with an abstract in English)

\section{Funding}

Research expenses have been paid by the researchers.

\section{Conflict of interest}

The authors declare that thay have no conflict of interest. 


\section{Author' biography with Photo}

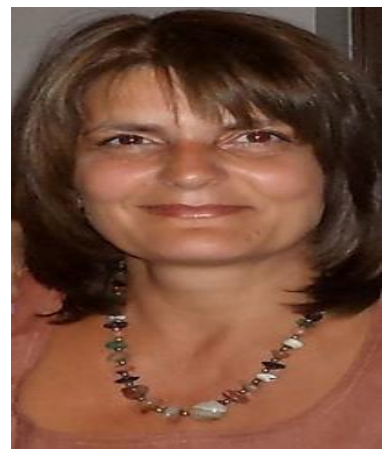

Name

Mailing address

\section{Emaillephone number}

\section{Nationality}

\section{Professional Qualifications}

Dates (from - to)

- Name and address of employer

- Type of business or sector

- Dates (from - to)

- Name and address of employer

- Type of business or sector

- Dates (from - to)

Name and address of employer

- Type of business or sector

\section{Academic Qualifications}

- Dates (from - to)
Mariela Stefanova Kamburova, MD, PhD

Major Assistant - Professor in the Faculty of Public Health,

Medical University - Pleven

\section{Bulgaria}

5800 Pleven,

14,"Georgy Kocev", Str.-63

mariela kamburova@yahoo.com

+35964884197 work number

Bulgarian

2006 - present Major Assistant -Professor in the Faculty of Public Health 2003 -2006 Senior Assistant - Professor in the Faculty of Public Health 1998 - 2003 Assistant - Professor in the Speciality „Health Care”

Medical University - Pleven; 1, "Sv. Kliment Ohridski”, Str., 5800 Pleven

Faculty of Public Health

Department of Public Health Sciences

1997 - 1998 Doctor

Medical University Hospital - Pleven

\section{Pleven}

Specialisation of Pediatrics

1996 - 1997 Doctor

Medical Hospital - Trojan

5600 Trojan

Head doctor responsible the village of Shipkovo

\section{April 2014}

PhD defance of thesis „Risk factors for prematurity and their impact on health and social needs in the development of children up to 3 - years of age"

$2012-2014$ 
PhD candidate

$2001-2003$

Medical University - Pleven

Qualification: Management Health Care, Master's degree

$1999-2002$

Higher Institute of Medicine - Pleven

Specialty in Public health

1989 - 1995

Higher Institute of Medicine - Pleven

Qualification: Medicine, Master's degree

1987 - 1989

Nursing school - Pleven

Qualification: General registered nurse

Membership:

1. European Public Health Association (EUPHA)

2. Balkan Medical Union

3. Bulgarian Medical Association

June 2015

Pleven, Bulgaria 